\title{
Gas Turbine Design and Matching Research of Waste Heat Recovery System for Marine Diesel Engine
}

\author{
Jiewei Peng, Zijian Zhang, Zhichao Gu and Peijun Qin \\ Shanghai Marine Diesel Engine Research Institute, Shanghai 200090, China
}

\begin{abstract}
With the emphasis on energy and environmental protection, energy-conservation and emission-reduction become vital issues for industrial development. Moreover, with the development of legislation on marine environment, the marine diesel engine has become focusing on energy saving and emission reduction for ships. For low-speed diesel engines under high load, waste heat from exhaust gas can be recovered by the compact and efficient gas turbine. In this paper, the matching design research between low speed diesel engine and gas turbine is carried out. To balance efficiency and compactness, the impeller was adjusted and generated by ANSYS BLADEGEN, based on 1D thermodynamic design. And the $1 \mathrm{D}$ calculation is similar to the ANSYS CFX simulation result: the total-static efficiency is $73.8 \%$ compared to $76.7 \%$. Moreover, the flow separation happened at the impeller suction side and created vortex due to the high incidence angle. The off-design operating point simulation of the turbine shows though the pressure ratio increase will cause the efficiency to decline a little, the total shaft power rises. In sum, this paper worked out a power turbine suitable for a low-speed diesel engine according to the turbine character matching design and simulation, which provides foundation to the construction of a steady operation of waste heat recovery system for marine diesel engine.
\end{abstract}

Key words: Waste heat recovery, turbine design, marine diesel engine, CFX, aerodynamic analysis.

\section{Introduction}

With the rising of fuel price and the increasing voice of global energy saving and emission reduction, a more efficient and convenient energy recycling method is deadly needed. According to the statistics, about $50 \%$ of the heat generated by marine diesel engine was exhausted in the form of waste gas, therefore, effective recovery and utilization of exhaust heat from marine diesel engine is significant for improving the efficiency of heat utilization and reducing the environmental pollution caused by exhaust emissions.

At present, the major wasted heat recovery technologies are mainly as followed: turbocharging, turbo compound generator (also called turbocompounding), Brayton cycle, Rankine engine cycle and thermoelectric generators [1-7]. Among them, the turbocompounding technology converts the

Corresponding author: Jiewei Peng, master, research field: waste heat recovery. waste energy into electric or mechanical energy by gas turbine. Aghaali and Angstrom [8] compared different recovery technologies and concluded turbocompounding can not only decrease brake specific fuel consumption (BSFC), but also simplify the structure so as to reduce the volume. Based on the expansion ratio of power turbine, that paper divided the turbocompounding into low-pressure turbocompounding (LP) and high-pressure turbocompounding (HP). In addition, different kinds of integration and structure of turbocompoundings have been analyzed, proving that the turbocompounding configuration affects both the performance of the power turbine and the operating characteristics of the diesel engine [9-11].

Apart from the configuration of turbocompounding system, the design of power turbine is the core aspect of waste heat recovery. Mamat et al. [12] designed a turbine with a low expansion ratio (1.1), whose exit-to-inlet area ratio is much smaller than the empirical value. In order to improve the turbine 
efficiency, Alshammari et al. [13] adopted a non-zero blade angle.

In this paper, a low-speed diesel engine is taken as the research object, and the matching design of power turbine is carried out. In order to improve the compactness of the $100 \mathrm{~kW}$ class power turbine designed by this paper, the structure design and optimization of the turbine were carried out, and the multi-condition aerodynamic simulation analysis was carried out by CFX.

\section{1D Thermodynamic Design}

\subsection{Turbine Matching}

The power turbine in this thesis is designed according to a low speed diesel engine. The parameters of this type of diesel engine at $100 \%$ load are as follows: exhaust flow rate is $8.79 \mathrm{~kg} / \mathrm{s}$, exhaust temperature is $392{ }^{\circ} \mathrm{C}$, exhaust pressure is $382 \mathrm{kPa}$. In order to recover the heat without impacting the diesel engine, turbocompounding is parallel connection with the turbocharger. The matching data between diesel engine and power turbine are obtained by calculation, as shown in Table 1.

It shows that under $100 \%$ loading, the power turbine can recover $145.9 \mathrm{~kW}$ electric energy when bypassing $0.76 \mathrm{~kg} / \mathrm{s}$ exhaust gas, while the system energy recycling rate is about $1.32 \%$. Therefore the input parameter of the power turbine could be set as shown in Table 2.

\subsection{Calculation}

The expansion ratio of the power turbine is about 3.75, which is low to a radial turbine. Thus, the subsonic guide vane was utilized to improve aerodynamic performance of the stator and the adaptability of the turbine at various operating point. The Mach number $M_{3}$ at the exit of stator is less than 0.95. According to the research findings [14] made by Institute of Mechanics, CAS (Chinese Academy of Sciences) (shown in Fig. 1), lower Mach number may cause a higher energy loss, which would worsen the stator performance. Thus, the $M_{3}$ above 0.7 is adopted in this paper.

According to Ref. [15], the energy losses are mainly as follows in Table 3.

\subsection{Optimization of 1D Calculation Results}

The paper has designed three turbine cases as shown in Table 4 . The case 1 provide a turbine with 30,000 rpm and impeller diameter $266.6 \mathrm{~mm}$, which offer a total-static efficiency of $79.7 \%$ and a shaft power of $142.3 \mathrm{~kW}$. However, case 1 results in an excessively large impeller diameter, thus the case 2 was worked out to improve it.

Table 1 Load characteristics of power turbine waste heat recovery system.

\begin{tabular}{lllll}
\hline Load & $50 \%$ & $75 \%$ & $85 \%$ & $100 \%$ \\
\hline Diesel power/kW & $2,170.6$ & $3,138.4$ & $3,626.6$ & $4,235.5$ \\
Turbine power/kW & 35.3 & 90.7 & 108.1 & 145.9 \\
Turbine energy recovery rate/\% & 1.63 & 2.89 & 2.98 & 3.44 \\
System energy recovery rate/\% & -2.33 & 0.54 & 0.78 & 1.32 \\
Bypass flow/kg.s ${ }^{-1}$ & 0.41 & 0.62 & 0.68 & 0.80 \\
\hline
\end{tabular}

Turbine energy recovery rate $=$ Turbine power/Diesel power;

System energy recovery rate $=($ Turbine power + Diesel power - Original diesel power $) /$ Low calorific value .

Table 2 Power turbine design parameters.

\begin{tabular}{ll}
\hline Inlet pressure $/ \mathrm{kPa}$ & 380 \\
Inlet temperature $/{ }^{\circ} \mathrm{C}$ & 480 \\
Exit pressure $/ \mathrm{kPa}$ & 101.3 \\
Exhaust gas flow $/ \mathrm{kg} \cdot \mathrm{s}^{-1}$ & 0.8 \\
\hline
\end{tabular}




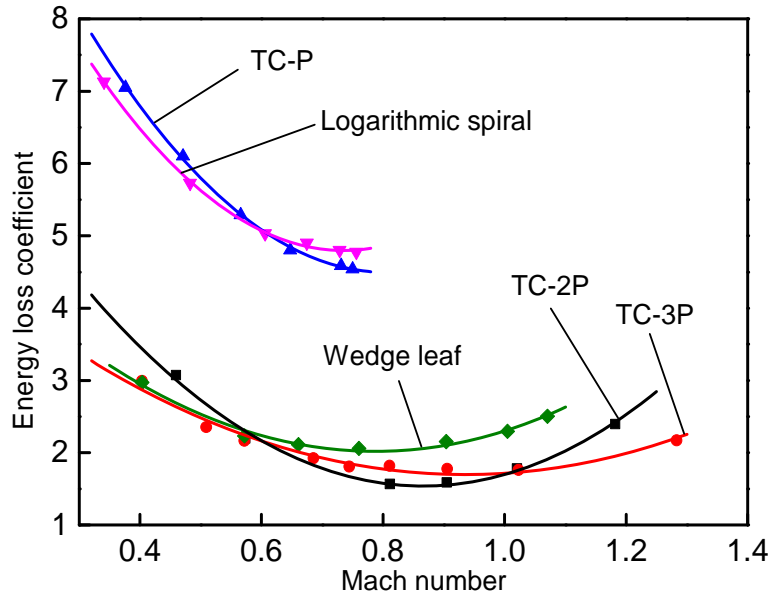

Fig. 1 Comparison of aerodynamic performance of several guide vanes.

Table 3 Mainly energy loss coefficients for power turbine.

\begin{tabular}{llll}
\hline Wheel friction loss power & $N_{f}=f \rho_{4} D_{4}^{2}\left(\frac{u_{4}}{100}\right)^{3} \frac{1}{1.36}$ & Impeller inlet blocking factor & $\tau_{4}=1-\frac{Z_{r} \Delta_{4}}{\pi D_{4} \sin \beta_{4 b}}$ \\
Impeller exit blocking factor & $\tau_{5}=1-\frac{\Delta_{5} Z_{r}}{\pi D_{5} \sin \beta_{5 b}}$ & Relative residual loss & $\zeta_{c 5}=\left(\frac{c_{5}}{c_{a}}\right)^{2}$ \\
Leakage loss coefficient & $\eta_{\Delta}=1-1.3 \cdot \frac{\Delta_{r}}{l_{m}}$ & Partial Intake Loss Coefficient & $\eta_{e}=1-\left(\frac{0.27}{\sqrt{e}}-0.27\right)$ \\
\hline
\end{tabular}

$f$ : friction loss coefficient

$D_{4}$ : impeller inlet diameter, $\mathrm{m}$

$Z_{\mathrm{r}}$ : number of rotor blade

$D_{5}$ : impeller exit diameter, $\mathrm{m}$

$c_{5}$ : absolute exit velocity, $\mathrm{m} / \mathrm{s}$

$\Delta_{\mathrm{r}}$ : impeller tip radial clearance, $\mathrm{m}$

$e$ : partial intake coefficient $\rho_{4}$ : exhaust density at impeller inlet, $\mathrm{kg} / \mathrm{m}^{3}$

$u_{4}$ : rotor blade speed at the inlet, $\mathrm{m} / \mathrm{s}$

$\Delta_{4}$ : mean blade thickness at impeller inlet, $\mathrm{m}$

$\beta_{5 \mathrm{~b}}$ : impeller exit blade angle, ${ }^{\circ}$

$c_{\mathrm{a}}$ : ideal expansion velocity, $\mathrm{m} / \mathrm{s}$

$l_{\mathrm{m}}$ : mean impeller blade height, $\mathrm{m}$

Table 4 Comparison of 1D design case of power turbine.

\begin{tabular}{llll}
\hline Parameters & Case 1 & Case 2 & Case 3 \\
\hline Rotational speed/rpm & 30,000 & 50,000 & 30,000 \\
Velocity ratio & 0.60 & 0.56 & 0.46 \\
Impeller diameter/mm & 266.6 & 149.3 & 204.4 \\
Reaction & 0.55 & 0.60 & 0.60 \\
Inlet absolute angle/ ${ }^{\circ}$ & 18.11 & 20 & 18.11 \\
Incidence angle/ $^{\circ}$ & -3.04 & -2.94 & 10.84 \\
Wheel diameter ratio $_{\text {Exit blade angle }{ }^{\circ}}$ & 0.4 & 0.5 & 0.4 \\
Total-static efficiency $_{\text {Shaft power/kW }}$ & 30 & 35 & 30 \\
\hline
\end{tabular}

In case 2 the impeller diameter is reduced to 149.3 $\mathrm{mm}$ by raising the rotating speed and optimizing some structure. Comparing case 1 and case 2, although the total-static efficiency in case 2 is lower, the wheel friction loss is not higher (17.6 kW in case 1 and 4.7 $\mathrm{kW}$ in case 2). Due to its lower velocity ratio and impeller diameter, the shaft power in case 2 is similar to case 1 . 

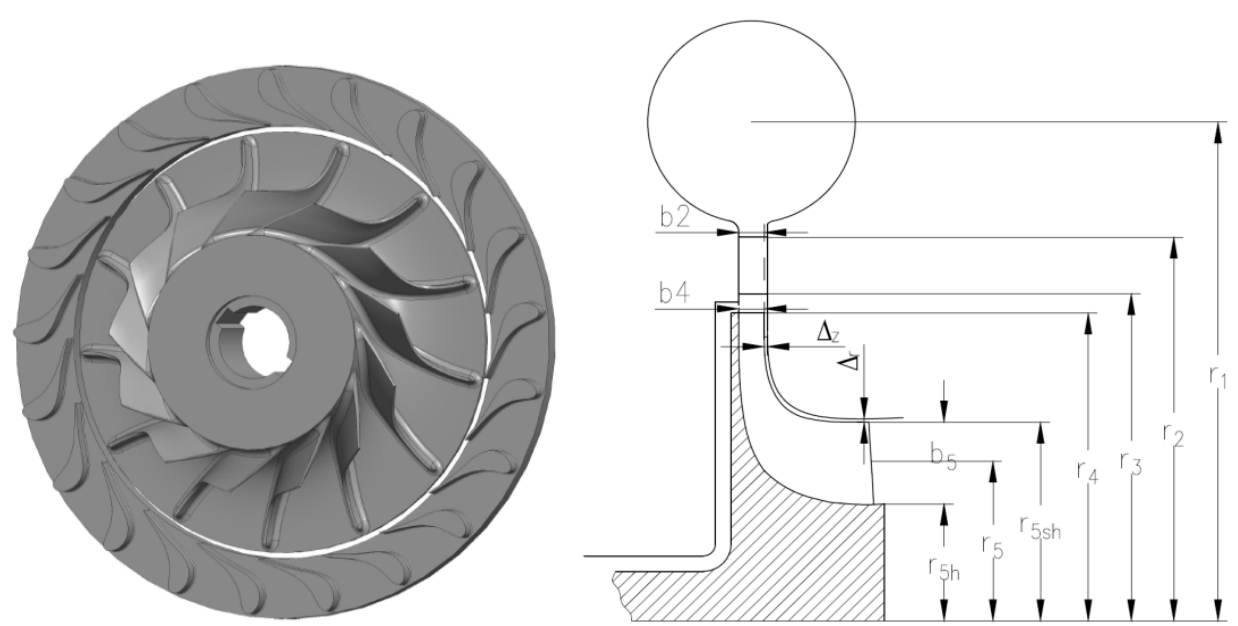

Fig. 2 Geometries of the stator and rotor and the turbine parameters.
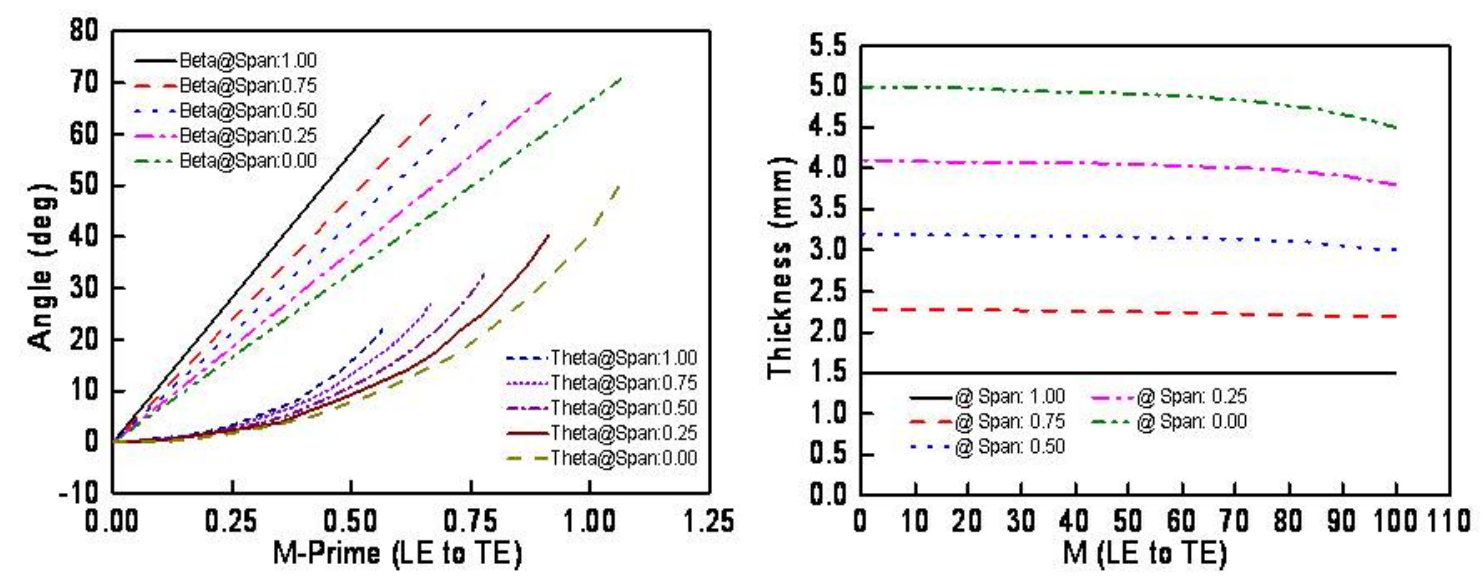

Fig. 3 Layered distribution of rotor blade angle and thickness.

Nonetheless, the raising of the rotating speed in case 2 causes a series of other design difficulties as: shaft design, seal design, bearing and generator selection. With the aim of limiting the rotating speed under $30,000 \mathrm{rpm}$, the case 3 was worked out by decreasing the velocity ratio to 0.46 , which shortens the impeller diameter to $76.7 \%$ compared to the case 1 . Though the total-static efficiency was lowered, the shaft power is still acceptable as $128.7 \mathrm{~kW}$.

Therefore, regarding the rotational speed, size and efficiency, the paper takes case 3 as the most balancing design, whose data are based on the 3D flow channel design of the turbine.

\section{Detailed Design of Turbine}

The stator blade exit Mach number is about 0.866 calculated by 1D model. As shown in Fig. 1, TC-2P blade shape is the most suitable as its energy loss efficiency is the least under such circumstance. The stator's 3D model is shown in Fig. 2.

The rotor designed by controlling means camber line and blade thickness, the mean camber line is defined mainly by blade angle and enveloping angle, the blade surface is defined mainly by mean camber line and blade thickness. Fig. 3 shows a plot of blade angle or thickness versus normalized meridional coordinate from leading edge to trailing edge.

Furthermore, the impeller tip clearance should be considered as well, because it dramatically influences the turbine efficiency [16] and furthermore, the safety. Regarding the impeller would expand under high 
temperature, the radial and axial clearance are both set to $0.5 \mathrm{~mm}$.

From what has been discussed above, the turbine detailing design data are shown in Table 5.

\section{Aerodynamic Simulation}

\subsection{D Flow Field Analysis}

After detailling design as above, the 3D model of the turbine was constructed by ANASYS Bladegen. Through the grid-independent verification, the meshed results are shown in Fig. 4.

The simulation results under design point are simulated by CFX and shown in Figs. 5 and 6, which give the temperature, pressure, velocityat $50 \%$ spanwise. The contours and pressure distribution curves show that the flow accelerates gently at forehead while fiercely at the throat, and deflects under the guidance of the vane. Correspondingly, the temperature and pressure changed gently at the beginning and then lowered dramatically.

Meanwhile the velocity decreases slightly at the gap between stator and rotor, showing the flow mixed in the gap. Such mixture makes the gas tend to be even at the inlet of rotor and contributes to the noise reduction and erosion prevention.

Moreover, the flow separation was happened at the impeller suction side, and thus created vortex. This is mainly due to the reduction of impeller diameter according to the case 3 in Table 4 . The positive incidence angle at $10.84^{\circ}$, directly caused the flow separation on the impeller blade suction side. As a result, the turbine efficiency is declined by additional energy losses.

As shown in Fig. 6, the pressure at the rotor blade pressure side changes smoothly and gently, proving the steady and continuous work on the impeller. On the other side, due to the flow separation, the suction side exists a $28 \mathrm{kPa}$ low pressure area, nevertheless, the pressure recovered rapidly and kept stable. Moreover, under the forces driven by hub and rotor blades, the gas was deflected causing pressure increase to $139 \mathrm{kPa}$ at $10 \%$ spanwise.

Table 5 Turbine geometric parameters.

\begin{tabular}{cccccccc}
\hline & Input conditions & \multicolumn{3}{c}{ Volute } & \multicolumn{2}{c}{ Stator } & \multicolumn{2}{c}{ Rotor } \\
\hline$T_{1}$ & $753.15 \mathrm{~K}$ & $r_{1}$ & $180 \mathrm{~mm}$ & vane & TC-2P & $r_{4}$ & $102.75 \mathrm{~mm}$ \\
$p_{1}$ & $380 \mathrm{kPa}$ & $M_{\mathrm{V}}$ & 0.068 & $r_{2}$ & $138.5 \mathrm{~mm}$ & $b_{4}$ & $6.8 \mathrm{~mm}$ \\
$G$ & $0.8 \mathrm{~kg} / \mathrm{s}$ & & $b_{2}$ & $6.8 \mathrm{~mm}$ & $\beta_{4 \mathrm{~b}}$ & $90^{\circ}$ \\
$p_{5}$ & $101.3 \mathrm{kPa}$ & & $r_{3}$ & $108.5 \mathrm{~mm}$ & $r_{5 \mathrm{sh}}$ & $75.95 \mathrm{~mm}$ \\
& & & $b_{3}$ & $6.8 \mathrm{~mm}$ & $r_{5 \mathrm{~h}}$ & $53.7 \mathrm{~mm}$ \\
& & & $Z_{\mathrm{s}}$ & 21 & $b_{5}$ & 22.25 \\
& & & $\alpha_{3}$ & 18.11 & $\beta_{5 \mathrm{~b}}$ & 30 \\
& & & $M_{3}$ & 0.866 & $Z_{\mathrm{r}}$ & 13 \\
& & & $O_{\text {throat }}$ & $9.7 \mathrm{~mm}$ & $\Delta_{\mathrm{r}}$ & $0.5 \mathrm{~mm}$ \\
& & & & & $\Delta_{\mathrm{z}}$ & $\mathrm{mm}$ \\
\hline
\end{tabular}
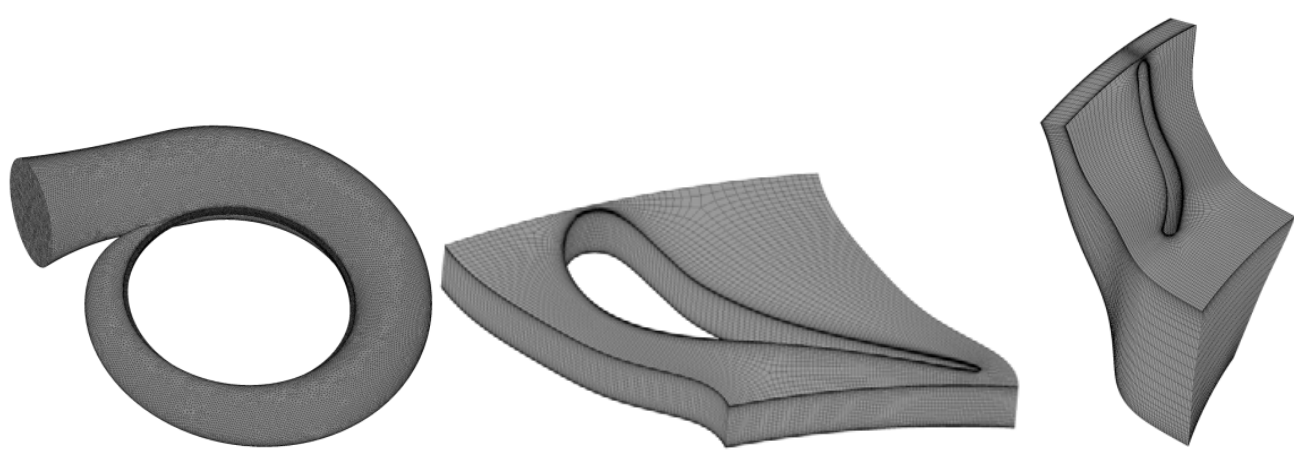

Fig. 4 Meshed volute, stator and rotor. 

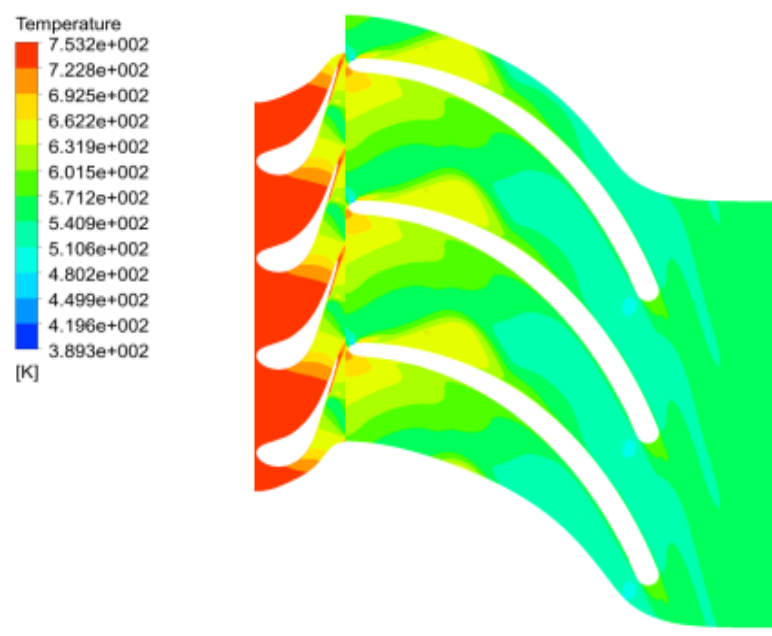

(a) Temperature
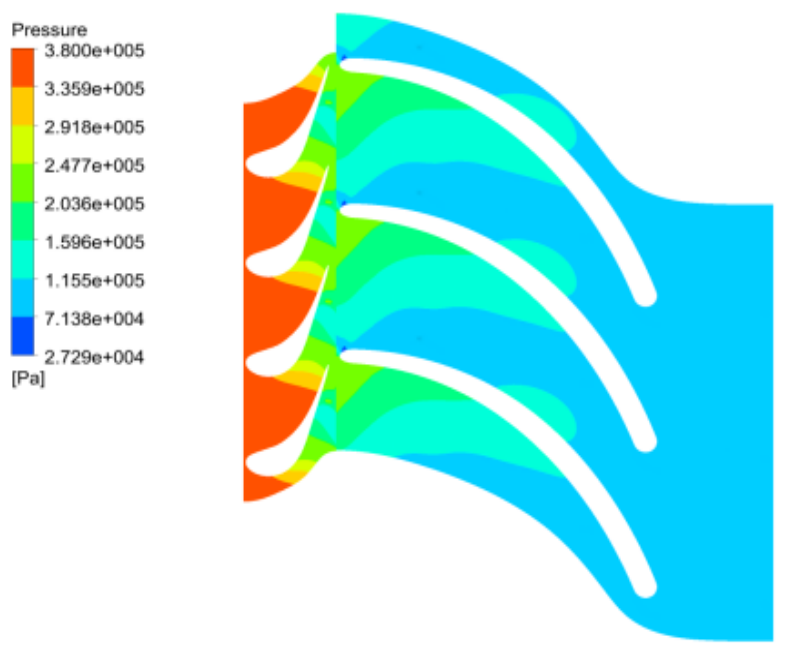

(b) Pressure
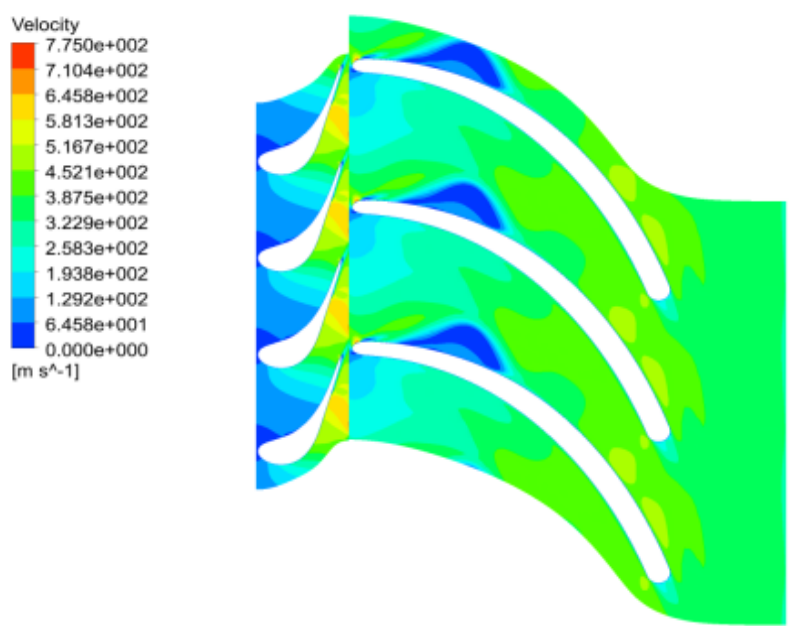

(c) Velocity

Fig. 5 The contours of temperature, pressure and velocity at $50 \%$ spanwise.
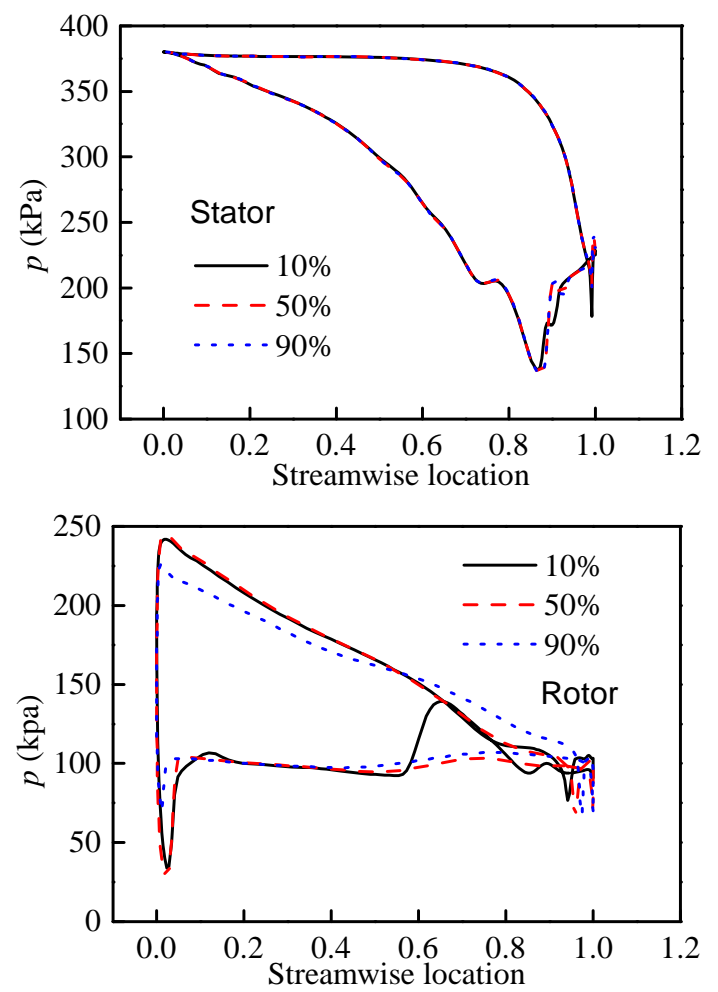

Fig. 6 Stator and rotor blade pressure distribution at 10\%, $50 \%$ and $90 \%$ streamwise.

\subsection{Off-Design Operating Point Simulation}

In order to analyze the turbine working characterunder off-design operating point, the paper simulates different gas flow and rotational speed under turbine inlet temperature $480{ }^{\circ} \mathrm{C}$ and exit pressure $103.4 \mathrm{kPa}$. The rotational speed ranges from 26,000 to $32,000 \mathrm{rpm}$, and the mass flow ranges from 0.5 to $0.85 \mathrm{~kg} / \mathrm{s}$.

As shown in Fig. 7a, it is easy to conclude that the specific flow rate $G_{\mathrm{S}}$ increases as pressure ratio $p_{\mathrm{S}}$ raises, while the specific speed $n_{\mathrm{S}}$ increases as $p_{\mathrm{S}}$ decreases.

In addition, as can be seen from Fig. 7b, the turbine efficiency curves at each $n_{\mathrm{S}}$ are approximately parallel to each other. The decreasing of $p_{\mathrm{S}}$ or increasing of $n_{\mathrm{S}}$, causes a lower incidence angle, which reduces the energy loss due to the flow separation, thus helping to improve turbine efficiency. Therefore, in the process of working with diesel engine, turbine's output power could be increased effectively when the exhaust 


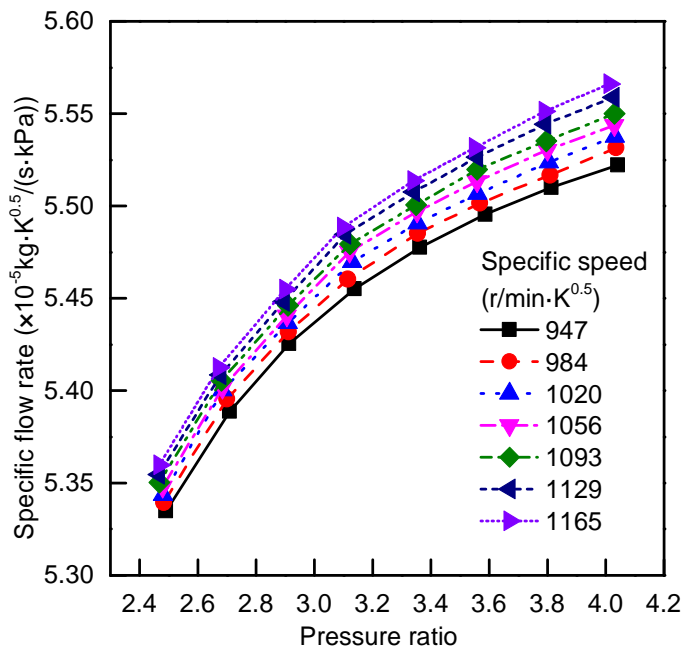

(a) Specific flow rate

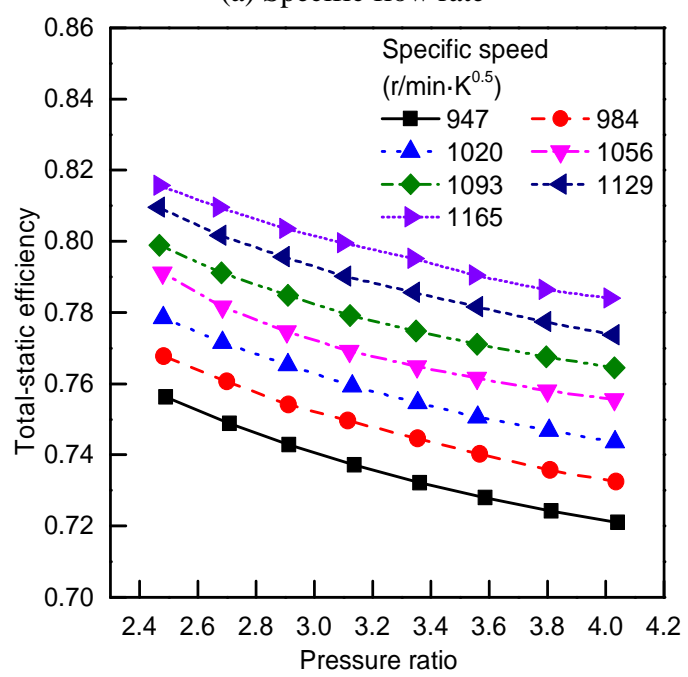

(b) Total-static efficiency

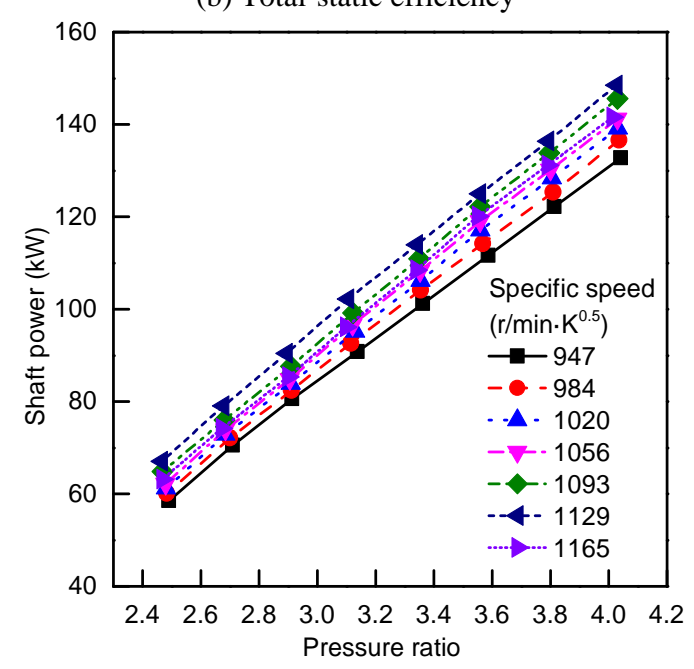

(c) Shaft power

Fig. 7 Characteristic curves of power turbine for off-design operating point. pressure increases, but the power turbine efficiency would decrease slightly ( $p_{\mathrm{S}}$ increases by 0.1 as $\eta_{\mathrm{ts}}$ decreases by about $0.2 \%)$.

According to the power characteristic curves as shown in Fig. 7c, the turbine shaft power increases with the specific speed as the rotational speed varies from 947 1,129, however, the power drops significantly while the specific speed continues to increase to 1,165 . This means that to ensure maximum turbine power, there is an optimum value for specific speed, about 1,129. The optimum specific speed corresponds to $30,000 \mathrm{rpm}$ at $480{ }^{\circ} \mathrm{C}$.

\section{Conclusions}

In order to recover the exhaust gas and improve the heat utilizing efficiency, this paper analyzed the matching character between one type of low-speed diesel engine and the power turbine by one dimension calculation. By comparing three design cases and balancing the efficiency and compactness, part of efficiency was sacrificed so as to reduce the speed ratio to 0.46 and impeller diameter reduce 23.3\% (compared to the original case 1).

Furthermore, this paper made detailing structure designed aided by ANASYS based on the one dimension design. The 3D aerodynamic simulation is analyzed by CFX. The simulation shows that in the stator gas flow accelerates gently at forepart while fiercely during the throat and deflected under guidance of vanes, meanwhile the flow separation happened at the impeller suction side and created vortex which is mainly due to the high incidence angle.

Totally the inside flow field of the turbine is smoothly and averagely, which meets the requirement. The off-design operating point simulation of the turbine shows though the pressure ratio increase will cause the efficiency to decline a little, the total shaft power rises. On the other side when the turbine works on $30,000 \mathrm{rpm}$, it possesses the optimum shaft power and efficiency. 


\section{References}

[1] Zhao, R., Zhuge, W., Zhang, Y., et al. 2014. "Parametric Study of Power Turbine for Diesel Engine Waste Heat Recovery.”Applied Thermal Engineering 64: 308-19.

[2] Edwards, K. D., Wagner, R. M., and Briggs, T. 2010. "Investigating Potential Light-Duty Efficiency Improvements through Simulation of Turbo-Compounding and Waste-Heat Recovery Systems.” SAE Technical Papers, 2019-01-2209.

[3] Shu, G., Liang, Y., Wei, H., et al. 2013. “A Review of Waste Heat Recovery on Two-Stroke IC Engine Aboard Ships.” Renewable and Sustainable Energy Reviews 19: 385-401.

[4] Rahbar, K., Mahmoud, S., Al-dadah, R., et al. 2015. "Preliminary Mean-Line Design and Optimization of a Radial Turbo-Expander for Waste Heat Recovery Using Organic Rankine Cycle.” Energy Procedia 75: 860-6.

[5] Kim, J., Kim, D., and Kim, Y. 2019. "Experiment on Radial Inflow Turbines and Performance Prediction Using Deep Neural Network for the Organic Rankine Cycle.” Applied Thermal Engineering 149: 633-43.

[6] Teo, A., Chiong, M., Yang, M., et al. 2019. "Performance Evaluation of Low-Pressure Turbine, Turbo-Compounding and Air-Brayton Cycle as Engine Waste Heat Recovery Method.” Energy 166 (1): 895-907.

[7] Yang, Y., Wang, S., and He, W. 2019. "Simulation Study on Regenerative Thermoelectric Generators for Dynamic Waste Heat Recovery.” Energy Procedia 158: 571-6.

[8] Aghaali, H., and Angstrom, H. 2015. "A Review of Turbocompounding as a Waste Heat Recovery System for
Internal Combustion Engines.” Renewable and Sustainable Energy Reviews 49: 813-24.

[9] Wei, W., Zhuge, W., Zhang, Y., et al. 2010. "Comparative Study on Electric Turbo-Compounding Systems for Gasoline Engine Exhaust Energy Recovery.” ASME paper, GT2010-23204.

[10] Hopmann, U., and Algrain, M. C. 2003. "Diesel Engine Electric Turbo Compound Technology.” SAE Int., 2003-01-2294.

[11] Hountalas, D. T., Katsanos, C. O., and Lamaris, V. T. 2007. "Recovering Energy from the Diesel Engine Exhaust Using Mechanical and Electrical Turbocompounding.” SAE Int., 2007-01-1563.

[12] Mamat, A. M. I., Padzillah, M. H., Romagnoli, A., et al. 2011. "A High Performance Low Pressure Ratio Turbine for Engine Electric Turbocompounding.” ASME paper, GT2011-45541.

[13] Alshammari, F., Karvountzis-Kontakiotis, A., and Pesiridis, A. 2017. "Radial Expander Design for an Engine Organic Rankine Cycle Waste Heat Recovery System.” Energy Procedia 129: 285-92.

[14] Hudong Shipbuilding Manufacturing Technology Group. 1978. "Compressor Modeling Test of GZ750 Turbocharging." Institute of Mechanics, Chinese Academy of Sciences.

[15] Li, Y., and Lu, G. 1987. Centripetal Turbine and Centrifugal Compressor. Beijing, China: China Machine Press.

[16] Lu, G. 1984. Determination of Airflow Parameters in Radial Leafless Space. Shanghai Jiaotong University Technology, No. 4. 